http://dx.doi.org/10.32929/2446-8355.2019v28n4p376-395

\title{
ESTRUTURA E PADRÃO DE DISTRIBUIÇÃO ESPACIAL DE UMBUZEIRO EM AGROECOSSISTEMAS DO AGRESTE DA PARAÍBA
}

\author{
Ewerton José de Medeiros Torres ${ }^{1 *}$, Nivânia Pereira da Costa ${ }^{2}$, Alex da Silva Barbosa ${ }^{3}$, \\ Robson Luis Silva de Medeiros ${ }^{4}$, Ronaldo Costa da Silva ${ }^{5}$, Miguel Avelino Barbosa Neto ${ }^{6}$ \\ ${ }^{1}$ Engenheiro Agrônomo, Dr. em Extensão Rural, Universidade Federal de Santa Maria (UFSM), Santa Maria, \\ RS. *E-mail do autor correspondente: ewerton@agronomo.eng.br. \\ ${ }^{2}$ Docente da Universidade Federal da Paraíba (UFPB), Dr $^{\mathrm{a}}$ em Agronomia / Genética e Melhoramento de \\ Plantas, Universidade Estadual Paulista Júlio de Mesquita Filho (UNESP), Bananeiras, PB. \\ ${ }^{3}$ Docente da Universidade Federal da Paraíba (UFPB), Dr. em Agronomia (UFPB), Bananeiras, PB. \\ ${ }^{4}$ Licenciado em Ciências Agrárias, Doutorando do Programa de Pós-Graduação em Agronomia / Produção \\ Vegetal (UNESP), Jaboticabal, SP. \\ ${ }^{5}$ Graduando em Engenharia de Minas, Universidade Federal de Campina Grande (UFCG), Campina Grande, PB. \\ ${ }^{6}$ Licenciado em Ciências Agrárias, Mestre em Agronomia (UFPB) Areia, PB.
}

Recebido: 12/05/2019; Aceito: 28/10/2019

RESUMO: Estudos que abordem o manejo florestal sustentável na Caatinga ainda são escassos, sendo proporcionalmente o bioma brasileiro menos estudado e protegido. Objetivou-se com este trabalho caracterizar a estrutura e o padrão de distribuição espacial de populações de Spondias tuberosa Arruda de agroecossistemas em microrregiões do Agreste paraibano. Foram plotadas 60 parcelas não contíguas, com $10 \mathrm{~m}$ x $10 \mathrm{~m}$ dentro de uma área total de $1 \mathrm{~km}^{2}$ nos municípios de Soledade e Pocinhos (pertencentes à microrregião do Curimataú Ocidental), e em Solânea e Cacimba de Dentro (Curimataú Oriental). As mensurações de diâmetro da base foram feitas com o auxílio de suta dendrométrica e paquímetro digital, e a altura aferida com o auxílio de tubos de PVC graduados. Os mapas de distribuição espacial em relação ao número de indivíduos por parcela, altura e diâmetro ao

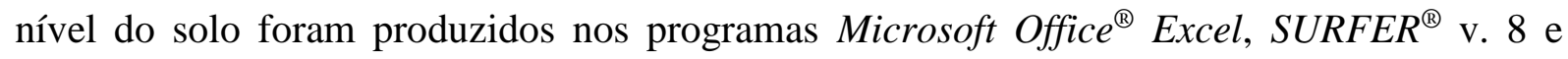
Corel $D R A W^{\circledR}$ v. $\mathrm{X} 4$, que revelaram que as áreas de Soledade e Solânea possuem melhor estado de conservação da espécie, quando comparadas às demais, sendo mais frequentes os indivíduos em recrutamento, ocorrendo maior abundância absoluta por área e possuindo padrão de tendência ao agrupamento. Nas caatingas de Pocinhos e Cacimba de Dentro ocorre ausência de indivíduos regenerantes, sendo encontrados somente indivíduos adultos em estádios ontogenéticos avançados e possuindo padrão de distribuição uniforme. Na caatinga de Soledade há maior densidade absoluta da espécie, e em Pocinhos a menor. Já em termos de frequência absoluta, Solânea detém a maior e Soledade a menor.

Palavras-chave: Spondias tuberosa Arruda. Ecologia de populações. Caatinga. Anacardiaceae. 


\title{
STRUCTURE AND PATTERN OF SPATIAL DISTRIBUTION OF UMBU TREE IN AGROECOSYSTEMS OF PARAÍBA'S AGRESTE
}

\begin{abstract}
Studies dealing with sustainable forest management in the Caatinga are still scarce, being the biome proportionally less studied and protected the Brazilian floral compositions. The aim of this study was to characterize the structure and spatial distribution pattern of populations of Spondias tuberosa Arruda of agroecosystems in micro-regions of Paraíba. 60 noncontiguous plots were plotted, grouped into six blocks, with 10m x 10m inside an area of $1 \mathrm{Km}^{2}$ in the municipalities of Soledade and Pocinhos (belonging to Westerner Curimataú), and Solânea and Cacimba de Dentro (Eastern Curimataú). The measurements of the diameter of the base were made with the aid of dendrometric and digital caliper, height measured with the aid of graduates PVC pipes. The spatial distribution maps in relation of the number of individuals per plot, height and diameter at ground level were produced in Microsoft Office ${ }^{\circledR}$ Excel, SURFER ${ }^{\circledR}$ v. 8 and Corel DRA $W^{\circledR}$ v. X4 programs, and revealed that the areas of Soledade and Solânea have better state of conservation of the species when compared to the other the areas, more frequent individuals in recruitment, occurring most absolute abundance by area and having standard tendency to cluster. In caatingas of Pocinhos and Cacimba de Dentro occurs absence of regenerating individuals, found only adults individuals in advanced ontogenetic stages and having standard uniform distribution. In caatinga of Soledad there largest absolute density of the species, and lower the Pocinhos. In terms of absolute frequency, Solânea holds the largest and the smallest Soledad.
\end{abstract}

Key words: Spondias tuberosa Arruda. Population ecology. Caatinga. Anacardiaceae.

\section{INTRODUÇÃO}

Notoriamente a Caatinga tem sido ocupada a partir da exploração extrativista de seus recursos naturais, que nos últimos anos tem alcançado índices preocupantes, pois atingem os mais diferentes setores como a extração da madeira, a caça indiscriminada de animais silvestres, a extração de mel de abelha, a colheita de frutos nativos e de plantas consideradas medicinais, dentre outras (PEREIRA FILHO; SILVA; CÉZAR, 2013). Devido a isso, o número de estudos sobre a fitossociologia, manejo, uso do solo e composição florística deste Bioma tem aumentado a cada ano. No entanto, provavelmente, este é ainda o Bioma menos estudado e um dos que têm sofrido maior degradação, pelo uso desordenado e predatório, nos últimos 400 anos (ARAÚJO, 2007).

Em vista ao desconhecimento sobre a dinâmica dos ecossistemas e da vegetação da Caatinga, há muitos séculos vem ocorrendo uma sistemática devastação decorrente da ação antrópica nas áreas da pecuária extensiva, agricultura, e retirada de lenha e madeira, por exemplo (ARAUJO et al., 2012). Este tipo de exploração em um ambiente pouco conhecido e complexo poderá conduzir a um processo irreversível de degradação (SANTANA; SOUTO, 2006) como a desertificação.

Microrregiões como as do Curimataú, que estão entre as mais áridas do Estado da Paraíba, foram identificadas como núcleos com tendência ao processo de desertificação 
(ALVES; SOUZA; NASCIMENTO, 2009; GOMES; AZEVEDO; SILVA, 2009; SÁ SOBRINHO, 2010), sendo também consideradas como áreas prioritárias para conservação da biodiversidade da Caatinga (ARAÚJO; RODAL; BARBOSA, 2005).

O umbuzeiro (Spondias tuberosa Arruda), uma frutífera encontrada na Caatinga, de porte arbóreo, com valor econômico, social e ecológico já reconhecidos, é um importante representante das plantas xerófilas, principalmente pela adaptação do seu sistema radicular, sendo, de acordo com Neves e Carvalho (2005), um destacado representante das potencialidades desta região, pois está inserido na cultura do sertanejo, significando para este uma planta sagrada.

De acordo com Lopes et al. (2009), a espécie possui mais de um mecanismo de dormência, como, por exemplo a mecânica e a da maturação do embrião; bem como mais de um tipo de dispersão na natureza, sendo a mais comum, como afirmam Cavalcanti, Resende e Brito (2003), a realizada por diversos animais da fauna da Caatinga que se alimentam dos frutos, tendo na dispersão hidrocórica em riachos temporários uma grande relevância também. Além disso, apresenta uma regeneração baixa, devido à ausência ou à insuficiência de plantas jovens em seu ambiente natural, cuja causa tem sido atribuída à dificuldade de germinação das sementes, ao desmatamento ilegal, à utilização de sua madeira para carvoarias, e ao ataque de pragas nas sementes e no caule (CAVALCANTI; RESENDE; BRITO, 2003). Até mesmo por ser uma planta com crescimento lento, tem sido pouco cultivada (CAVALCANTI; RESENDE; BRITO, 2004).

Esses fatores desaceleram o processo de regeneração natural das espécies, que no caso das arbóreas em uma comunidade florestal, depende da produção de sementes, do estabelecimento das plântulas, da sobrevivência das mudas e do recrutamento (YADAV; GUPTA, 2009). Embora este processo de recomposição de vegetação nos ambientes semiáridos normalmente tenda a ser lento devido principalmente à dependência da precipitação, da dispersão das sementes, da existência de um banco de sementes viáveis no solo e da rebrota de tocos e raízes (PADILLA; PUGNAIRE, 2004). Esta situação se agrava ainda mais quando o local não oferece condições propícias, como em ambientes antropizados, a exemplo dos agroecossistemas com uso de pecuária extensiva, onde os animais, muitas vezes por falta de alimento, pastejam indivíduos regenerantes de muitas espécies vegetais.

O conhecimento dos padrões de distribuição espacial de espécies florestais em uma comunidade é uma das ferramentas mais utilizadas para fortalecer programas de recuperação e condução de sistemas de manejo adequados (ANJOS et al., 1998; ANJOS et al., 2004). Entendendo que estes fenômenos podem ser naturais como ter origem na ação antrópica, objetivou-se com este estudo caracterizar a estrutura e o padrão de distribuição espacial de populações de $S$. tuberosa Arruda em agroecossistemas nas microrregiões do Curimataú Oriental e Ocidental, localizadas no Agreste da Paraíba. 


\section{MATERIAL E MÉTODOS}

\section{Área de estudo}

O estudo foi desenvolvido em áreas experimentais localizadas nos municípios paraibanos de Pocinhos e Soledade, pertencentes à microrregião do Curimataú Ocidental e em Cacimba de Dentro e Solânea, que se encontram no Curimataú Oriental. Estas microrregiões são duas das 23 existentes no estado da Paraíba, pertencentes à Mesorregião do Agreste paraibano.

Para cada um dos quatro municípios, foi escolhida uma área amostral de agroecossistema que apresentava características de formações florestais com vegetação de Caatinga Hiperxerófila (com vegetação caducifólia espinhosa), com perturbação antrópica e registros prévios da ocorrência nativa de Spondias tuberosa Arruda, ou seja, nenhum indivíduo de umbuzeiro do estudo foi cultivado. Outro critério importante para a escolha dos locais foi a necessidade de se pesquisar dados inerentes ao ambiente onde as populações de umbuzeiro ocorriam naturalmente, com o objetivo de embasar as informações sobre a ecologia da família in loco. É importante destacar que os agroecossistemas eram compostos essencialmente de vegetação nativa, e verificou-se a presença de animais ruminantes, como bovinos, caprinos e ovinos, caracterizando agroecossistemas baseados na pecuária extensiva, podendo estes animais estar causando desequilíbrios na regeneração natural da espécie, em virtude do pastejo na vegetação natural.

A primeira área de caatinga está localizada no município de Soledade, PB, situada nas coordenadas geográficas $07^{\circ} 03^{\prime} 25^{\prime \prime} \mathrm{S}$ e $36^{\circ} 21^{\prime} 46^{\prime \prime}$. O município possui uma área de $560 \mathrm{~km}^{2}$, altitude aproximada de 551m, distando 165,5 km da capital João Pessoa (BRASIL, 2005d). Soledade apresenta três classes de solos (Neossolo, Planossolo e Luvissolo), possuindo também afloramentos de rochas (EMBRAPA, 2006; JACOMINE, 2009). A vegetação desta unidade é formada basicamente de Florestas Subcaducifólica e Caducifólica, próprias das áreas Agrestes; já o clima, de acordo com a classificação de Köppen-Geiger, é Bsh (equatorial semiárido), com temperatura máxima anual de $30^{\circ} \mathrm{C}$ e mínima de $18{ }^{\circ} \mathrm{C}$, com período de maior precipitação entre Fevereiro e Maio, com pluviosidade média anual de $391,7 \mathrm{~mm}$ (BRASIL, 2005d; FRANCISCO, 2010; AESA, 2015).

A segunda área, localizada no município de Pocinhos, PB, situado nas coordenadas 0704'37" S e 3603'39" O. Este município está inserido na unidade geoambiental do Planalto da Borborema, formada por maciços e outeiros altos, possuindo uma área de $630 \mathrm{~km}^{2}$, altitude aproximada de $646 \mathrm{~m}$, distando 132,2 km da capital João Pessoa (BRASIL, 2005b). Pocinhos apresenta duas classes de solos (Neossolo e Planossolo), ocorrendo também afloramento de rochas (EMBRAPA, 2006; JACOMINE, 2009). A vegetação, as temperaturas médias desta unidade são semelhantes às do município de Soledade, tendo precipitação $383,8 \mathrm{~mm} / \mathrm{ano}$ nos meses de Março a Junho. O clima, de acordo com a classificação de Köppen-Geiger é, na maior parte, Bsh (equatorial semiárido), e uma pequena parte do tipo As, com inverno úmido e verão seco (BRASIL, 2005b; FRANCISCO, 2010; AESA, 2015).

A terceira área, localizada no município de Cacimba de Dentro, PB, nas coordenadas 06³8'31" S e 3547'24" O. O município ocupa uma área de $239,7 \mathrm{~km}^{2}$, atingindo uma altitude 
aproximada de $536 \mathrm{~m}$, distando $125 \mathrm{~km}$ da capital João Pessoa (BRASIL, 2005a). Cacimba de Dentro apresenta duas classes de solos, Neossolo e Cambissolo (EMBRAPA, 2006; JACOMINE, 2009). A vegetação que recobre a região estudada é de Caatinga Hipoxerófila, com pequenas áreas de Florestas Caducifólias. O clima, segundo a classificação de KöppenGeiger, é As (clima tropical inverno úmido e verão seco), com temperatura máxima anual de $30{ }^{\circ} \mathrm{C}$ e mínima de $19{ }^{\circ} \mathrm{C}$, tendo período de maior precipitação de Março a Julho, marcando 721,0 mm/ano (BRASIL, 2005a; FRANCISCO, 2010; AESA, 2015).

A quarta área de estudo, situada no município de Solânea, PB, com altitude aproximada de $626 \mathrm{~m}$, possuindo as coordenadas $06^{\circ} 46^{\prime} 40^{\prime \prime} \mathrm{S}$ e $35^{\circ} 41^{\prime} 49^{\prime \prime} \mathrm{O}$. O município ocupa uma área de $266 \mathrm{~km}^{2}$, atingindo uma altitude aproximada de $626 \mathrm{~m}$, distando 99,3 km da capital João Pessoa (BRASIL, 2005c). Solânea apresenta o clima, a variação de temperatura e a precipitação nos mesmos valores de Cacimba de Dentro, que está na mesma microrregião (Curimataú Oriental), bem como as duas classes de solos está presente, além de uma porção de Argissolo. A vegetação e o clima desta unidade têm similaridade com as classificações de Soledade e Pocinhos, possuindo pluviosidade de 1505,6 mm/ano (BRASIL, 2005c; EMBRAPA, 2006; JACOMINE, 2009; FRANCISCO, 2010; AESA, 2015).

Em cada área de agroecossistema foram demarcadas 60 parcelas de $10 \mathrm{~m}$ x $10 \mathrm{~m}$, agrupadas em conglomerados de seis e instaladas em locais com a predominância de vegetação antropizada. Devido a própria característica ecológica da espécie, de ser dispersa no ambiente, o método utilizado foi o de parcelas não contíguas, numa área de $1 \mathrm{~km}^{2} \mathrm{de}$ Caatinga para cada área amostral dos quatro municípios (Figura 1). As plantas identificadas como $S$. tuberosa foram amostradas para o levantamento de dados de estrutura e todas que estavam localizadas dentro das parcelas amostrais foram inclusas no estudo.

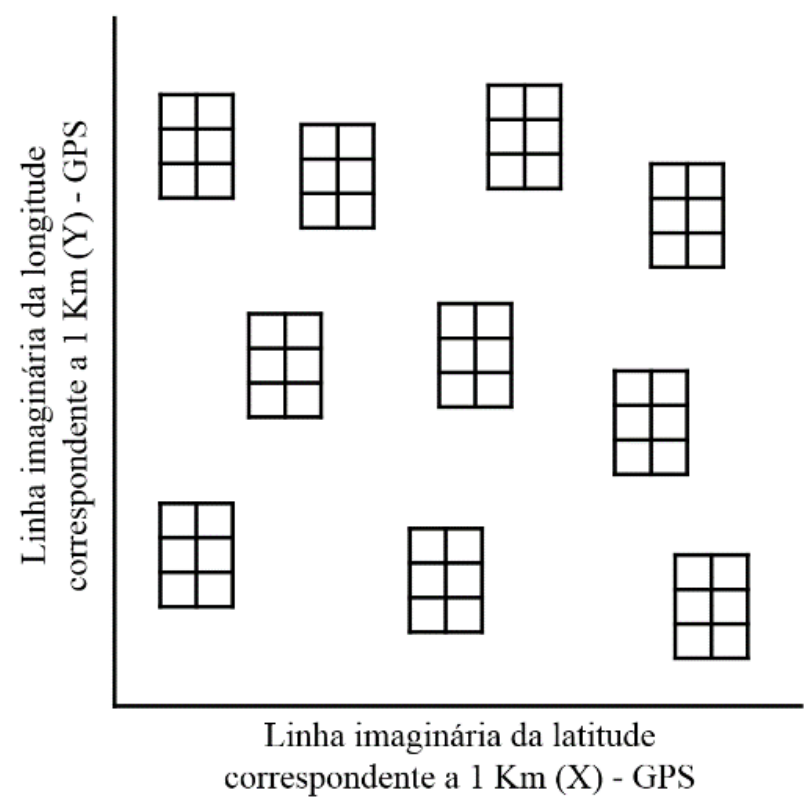

Figura 1. Croqui experimental de distribuição das parcelas nas áreas amostradas de vegetação nativa com ocorrência de Spondias tuberosa Arruda. Experimental sketch of distribution of plots in sampled areas of native vegetation with the occurrence of Spondias tuberosa Arruda. Fonte: Autoria própria. Own authorship. 


\section{Parâmetros estruturais avaliados e descritores de estrutura analisados}

Para a estrutura da população, foram consideradas duas variáveis: altura e diâmetro ao nível do solo. A altura dos indivíduos foi mensurada com auxílio de uma régua graduada, já para os indivíduos mais altos foram utilizadas varas tubulares graduadas de PVC (polyvinyl chloride ou policloreto de vinil) encaixáveis e pintadas de $1 \mathrm{~m}$ x $1 \mathrm{~m}$, que possuíam um comprimento máximo de $2 \mathrm{~m}$. Quando insuficientes, o comprimento vertical das varas encaixadas foi somado à altura do auxiliar de campo para se obter a estimativa da altura.

O diâmetro ao nível do solo foi aferido com auxílio de um paquímetro digital para indivíduos mais jovens, com caules mais finos, e com uma suta dendrométrica para os mais velhos.

O processamento dos dados para obtenção dos valores de estrutura horizontal foi realizado por meio do programa Microsoft Office ${ }^{\circledR}$ Excel 2013. Os descritores analisados foram: densidade absoluta (DA), frequência absoluta (FA) e dominância absoluta (DoA). Também foi calculado o índice de agregação (IGA), para saber o padrão de distribuição espacial da espécie. Os descritores e o índice são apresentados a seguir, com suas respectivas fórmulas e síntese dos postulados.

A densidade absoluta é a medida que expressa o número de indivíduos de uma dada espécie por unidade de área, sendo representada pela equação: DA = N/A. Em que: DA = densidade absoluta da espécie (ind. ha); $\mathrm{N}$ = número de indivíduos da espécie; $\mathrm{A}$ = área amostrada em quilômetro quadrado $\left(\mathrm{km}^{2}\right)$.

A frequência absoluta, expressa em porcentagem, é a relação entre o número de parcelas ou pontos que ocorre uma dada espécie e o número total de amostras: $\mathrm{FA}=(\mathrm{n} / \mathrm{Nt}) \mathrm{x} 100$. Em que: $\mathrm{FA}=$ frequência absoluta da espécie $(\%) ; \mathrm{n}=$ número de parcelas com a espécie; $\mathrm{Nt}=$ número total de parcelas amostradas.

A dominância absoluta é dada a partir da somatória da área basal dos indivíduos da espécie, dividido pela área total amostrada: DoA = Ab/A. Em que: DoA = dominância absoluta da espécie $\left(\mathrm{m}^{2} /\right.$ hectares $) ; \mathrm{Ab}=$ área basal da espécie $\left(\mathrm{m}^{2}\right) ; \mathrm{A}=$ área total amostrada $(\mathrm{km})$.

Para verificar o padrão de distribuição espacial da espécie nas áreas, determinou-se o Índice de Agregação (ou Índice de McGinnies) através da equação: IGA = D/d. Em que: D = número total de indivíduos da espécie / número total de parcelas alocadas, enquanto que $\mathrm{d}=$ ln (1-FA/100), sendo $\ln =$ logaritmo neperiano e FA = frequência absoluta (MCGINNIES, 1934). Dessa forma, sendo o valor do IGA < 1,0, a distribuição espacial é uniforme; em IGA $=1,0$, a distribuição é aleatória; em IGA > 1,0 e <2,0 há uma tendência ao agrupamento; e em IGA > 2,0 ocorre agregação.

Para analisar a distribuição dos indivíduos amostrados em relação às classes de altura foram construídos histogramas de frequência com intervalo de um metro (estrutura hipsométrica), os quais serviram também para a análise da regeneração da espécie. E para analisar a distribuição em relação ao diâmetro do caule foram elaborados histogramas de distribuição de frequência de classes de diâmetro com intervalos de $10 \mathrm{~cm}$ de todos os 
indivíduos amostrados. Os histogramas foram feitos com o auxílio do programa Microsoft Office ${ }^{\circledR}$ Excel 2013.

\section{Plotagem dos mapas e análise da distribuição espacial}

Para a plotagem dos mapas de distribuição espacial das árvores e das plantas jovens em regeneração foi realizado um mapeamento dos indivíduos dentro de parcelas amostrais utilizando GPS Garmin $^{\circledR}$ eTrex Venture ${ }^{\circledR}$ HC para a coleta das coordenadas de cada indivíduo em todas as áreas. O uso do equipamento para plântulas justifica-se pela característica natural da planta em ser dispersa no ambiente e limitada em áreas de agroecossistemas. O equipamento foi configurado para SAD-69 (Datum Sul Americano) e modo de coordenadas adotada foi o UTM (Universal Transverse Mercator). As coordenadas foram baixadas para o computador com auxílio do aplicativo MapSource Garmin $^{\circledR}$ e em seguida os bancos de dados foram compilados no Microsoft Office ${ }^{\circledR}$ Excel 2013.

Para a análise da distribuição espacial das plantas de $S$. tuberosa Arruda relacionando ao número de indivíduos por área, aos diâmetros dos caules e às alturas foram produzidos mapas de contorno bidimensionais de isolinhas. Este processo contou com o auxílio dos softwares Microsoft Office ${ }^{\circledR}$ Excel 2013, SURFER ${ }^{\circledR}$ v. 8 (Golden Software, Colorado, U.S.A.), e Corel DRAW $^{\circledR}$ v. X4. No SURFER ${ }^{\circledR}$ os dados foram levantados através da interpolação por meio da "Função de Base Radial" (Radial Basis Function), utilizando estatística univariada para a composição dos mapas.

Segundo Jakob (2002) um dos melhores métodos de análise de dados se baseia na interpolação de dados, pois os valores intermediários dos dados são preservados, e o resultado final é uma superfície contínua de dados mais suavizados, minimizando contrastes. A partir disto, o SURFER cria semivariogramas, com a função de base radial, elaborada por rotinas do programa, e como resultado, simulam a continuidade espacial, representando em isolinhas.

O valor interpolado para todos os pontos da malha dos mapas elaborados foi estimado pela seguinte equação:

$$
G_{j}=\sum_{i=1}^{N_{P T}} w_{i j} Z_{i}
$$

Em que: $G_{j}=$ valor do estimador para o ponto j; $N_{P T}=$ número de pontos usados para a interpolação; $Z_{i}=$ valor estimado no ponto i com valor conhecido; $W i j=$ peso associado ao valor estimado $\mathrm{i}$.

Ramalho (2008) afirma que praticamente todos os métodos de interpolação seguem essa equação. No método da Krigagem, os valores são variáveis de acordo com a variabilidade espacial expressa no semivariograma. Enquanto que no método de interpolação Radial Basis Function (RBF), os valores são variáveis de acordo com a função básica.

A função básica $(B(L))$, neste contexto, é uma função real de $L$ (distância (raio) a partir da origem). Uma das funções mais utilizada é a multiquádritica, representada por:

$$
B(L)=\sqrt{L^{2}+R^{2}}
$$


Sendo $B(L)$ uma função de ponderação do método multiquadrático e $\mathrm{R}^{2}$ um parâmetro suavizador especificado pelo usuário. Um valor comum para o $\mathrm{R}^{2}$ é situado entre a distância de amostragem média e a metade da distância da amostragem média (CARLSON; FOLEY, 1991).

Os mapas de distribuição espacial das isolinhas de S. tuberosa Arruda foram preparados na expectativa de comparar a distribuição dos indivíduos em cada área de caatinga considerada neste estudo.

\section{RESULTADOS E DISCUSSÃO}

A população das quatro áreas amostradas foi representada pelo registro de 54 indivíduos Spondias tuberosa Arruda dos quais 16 estavam no município de Soledade, 15 em Solânea, 12 em Cacimba de Dentro e 11 em Pocinhos.

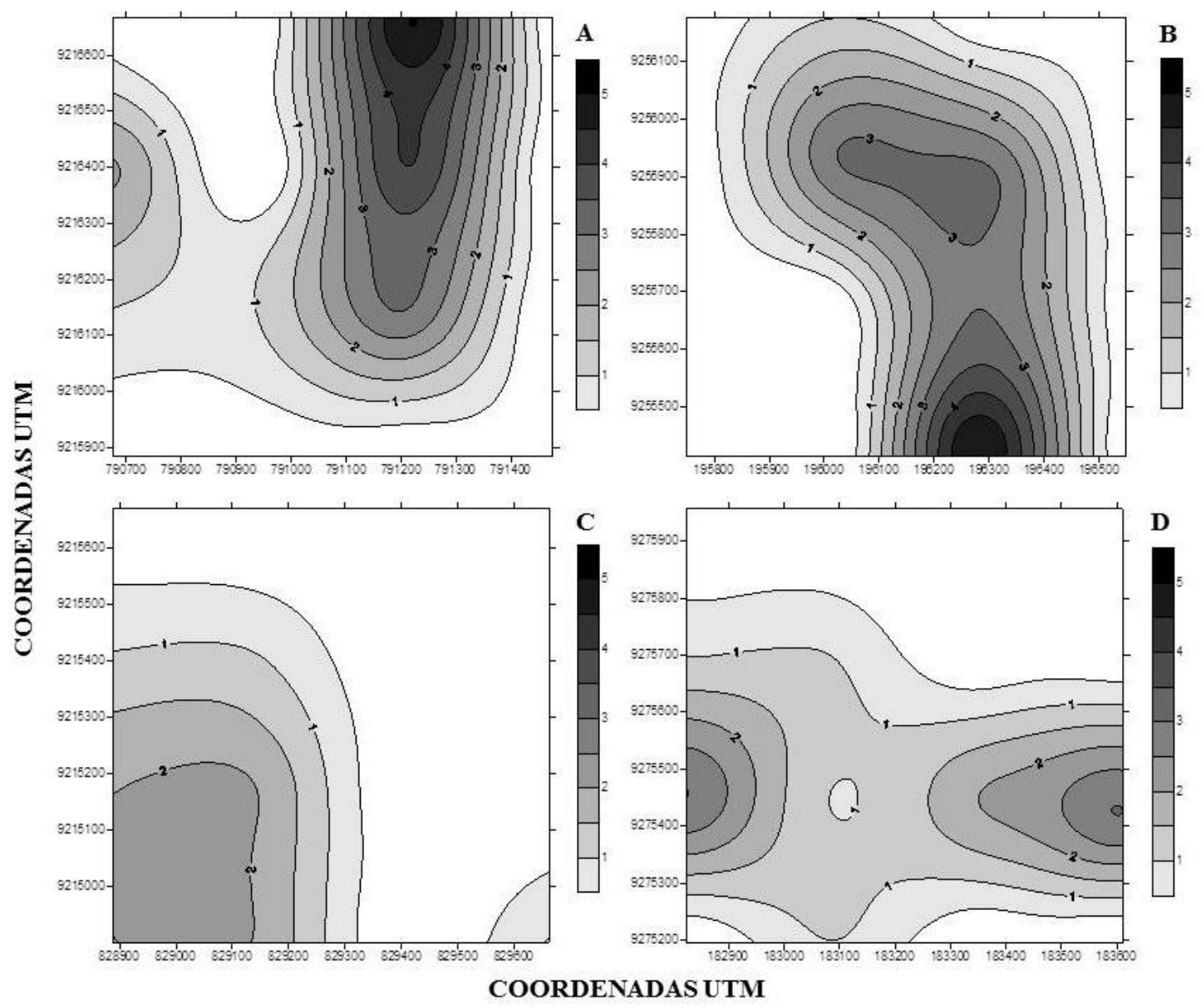

Figura 2. Mapa de disposição de isolinhas de números de indivíduos de Spondias tuberosa Arruda por parcela em quatro áreas de Caatinga, nos municípios de Soledade (A), Solânea (B), Pocinhos (C) e Cacimba de Dentro (D). Contour maps of numbers of individuals of Spondias tuberosa Arruda per plot in four areas of Caatinga, in the counties of Soledade $(A)$, Solânea (B), Pocinhos (C) and Cacimba de Dentro (D).

Fonte: Autoria própria. Own authorship. 
A Figura 2 apresenta a distribuição de isolinhas de números de indivíduos de $S$. tuberosa Arruda por parcela nas áreas de Caatinga. Em todas as Figuras deste trabalho as partes correspondentes à esquerda $(\mathrm{A} \mathrm{e} \mathrm{C})$ representarão as áreas do Curimataú Ocidental e as da direita (B e D), o Curimataú Oriental.

Nos mapas, as manchas mais claras correspondem a áreas com menor número de plantas e à medida que escurece, este número aumenta, representando um adensamento de plantas. Isto mostra que Pocinhos e Cacimba de Dentro são as áreas com menor número de indivíduos amostrados. Em contraposição, os mapas de Soledade e Solânea, possuem isolinhas que limitam manchas mais escuras, as quais são atribuídas a uma maior abundância absoluta por área.

As localidades de Soledade e Solânea possuem uma vegetação nativa mais fechada e nestes locais foram encontrados indivíduos jovens com facilidade, se comparadas às áreas de Pocinhos e Cacimba de Dentro, normalmente localizados em conglomerados e próximos a árvores de umbuzeiro mais antigas. Esta ocorrência corrobora para a informação contida na Figura 3 quanto ao adensamento nas referidas áreas, que são apresentadas as disposições dos indivíduos em nove classes de diâmetros de caule ao nível do solo nas quatro áreas de Caatinga estudadas.

Em Soledade foram encontrados indivíduos regenerantes protegidos em aglomerados de macambira (Bromelia laciniosa), planta da Caatinga da família das bromeliáceas, possuidora de folhas modificadas contendo espinhos que certamente serve de proteção física contra a predação por animais.

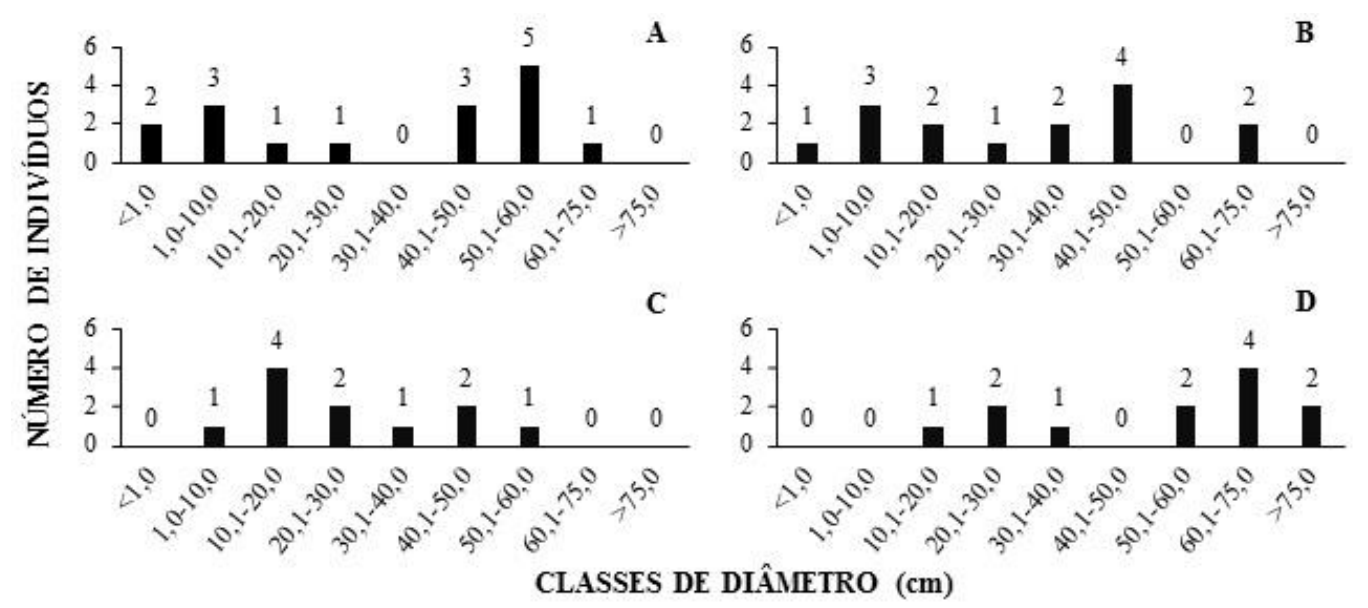

Figura 3. Estrutura diamétrica de Spondias tuberosa Arruda por parcela em quatro áreas de Caatinga, nos municípios de Soledade (A), Solânea (B), Pocinhos (C) e Cacimba de Dentro (D). Diametric structure of Spondias tuberosa Arruda per plot in four areas of Caatinga, in the counties of Soledade (A), Solânea (B), Pocinhos (C) and Cacimba de Dentro (D). Fonte: Autoria própria. Own authorship.

Em Solânea também foram encontrados indivíduos jovens próximos a plantas de $B$. laciniosa, e bem mais desenvolvidos que os de Soledade. Nos outros dois municípios restantes, não foram encontrados indivíduos na menor classe de diâmetro, característica que sugere uma maior antropização nos agroecossistemas destas localidades, visto que em locais mais preservados é possível encontrar indivíduos regenerantes. 
A partir da análise dos histogramas de frequência observou-se que na porção do Curimataú Ocidental, foi demonstrada em Soledade a predominância de indivíduos na sétima classe (31,25\%), seguida da segunda e sexta classes, ambas com 18,75\% (Figura 3A). Já em Pocinhos, que se localiza na mesma microrregião, a estrutura diamétrica evidenciou concentração de indivíduos na terceira classe (36,36\%), e posteriormente, com as mesmas porcentagens a quarta e sexta classes $(18,18 \%)$, na Figura 3C. No primeiro município existe uma maior variabilidade quanto à variação entre as classes de diâmetros, possuindo indivíduos de quase todas as espessuras de diâmetro. No segundo município, as menores classes tem poucos indivíduos $(>10 \mathrm{~cm})$, com maior abundancia na terceira classe com tendência a redução em quantidade à medida que ocorre o engrossamento dos caules.

No caso da estrutura diamétrica do Curimataú Oriental, foi verificado em Solânea a predominância de indivíduos na sexta classe (26,66\%), seguindo para a segunda classe (20\%), e igualando a terceira, quinta e oitava classes com 13,33\% (Figura 3B). Para o outro município dessa microrregião, Cacimba de Dentro, predominaram representantes nas classes de maiores diâmetros, tendo 33,33\% na oitava classe, igualando para as classes nona, sétima e quarta com 16,66\% (Figura 3D), e as menores classes $(>20,0 \mathrm{~cm}$ ) tem poucos indivíduos, com maior abundancia na terceira classe.

Neste estudo, todos os fragmentos apresentaram ausência de indivíduos em algumas classes diamétricas. Em Soledade e Solânea esta ausência foi verificada para as maiores classes, diferente de Pocinhos e Cacimba de dentro que não tiveram indivíduos na menor classe de diâmetro, reforçando a baixa presença de indivíduos regenerantes nestas duas últimas áreas. O Padrão de distribuição foi considerado anormal e para Alves Júnior et al. (2013) a distribuição dos diâmetros esperado para áreas nativas é com padrão em "J" invertido, concentrando o maior número de indivíduos nas menores classes. Para Lamprecht (1962) uma distribuição regular (maior número de indivíduos nas classes inferiores) é a maior garantia para a existência e sobrevivência das espécies, e ao contrário, quando ocorre uma estrutura diamétrica irregular, as espécies tenderão a desaparecer com o tempo.

A Figura 4 traz outra perspectiva da espécie com relação ao diâmetro, com a apresentação de mapas de distribuição de isolinhas das classes de diâmetro de S. tuberosa Arruda nas quatro áreas de Caatinga.

Nos mapas as manchas brancas próximas às cores escuras denotam que nestes locais não existem plantas, ou seja, é uma porção da área não amostrada, de acordo com a estatística univariada rodada no programa $S U R F E R^{\circledR}$, e as cores mais claras na escala de cinza significam indivíduos com diâmetro caulinar maior. Portanto, à medida que aumenta o calibre do caule, clareia a cor no mapa. Este padrão de cores em gradiente serve de modelo para os outros mapas adiante, sendo diferente da configuração dos primeiros mapas da Figura 2.

De acordo com a Figura 4, os diâmetros das plantas nos mapas variam numa escala de 1 a $70 \mathrm{~cm}$, diferindo apenas no mapa de Cacimba de Dentro, local onde foi amostrada a árvore com maior diâmetro, possuindo $190 \mathrm{~cm}$, outra com $80 \mathrm{~cm}$ e nenhum indivíduo com diâmetro abaixo de $10 \mathrm{~cm}$. 
Em Soledade observou-se que 7,70\% da área apresentou plantas com diâmetro de até 10 cm; em 6,36\% observou-se plantas com diâmetro variando entre 15 a $25 \mathrm{~cm}$; em 7,27\% amostrou-se plantas com diâmetros entre 30 a $40 \mathrm{~cm} ; 8,75 \%$ com plantas de diâmetro entre 45 a $55 \mathrm{~cm}$ e plantas com diâmetro superior a $60 \mathrm{~cm}$ somaram-se 5,79\% da área estudada (Figura 4A). Pode-se perceber que no mapa de Soledade aparece um grande espaço em branco; isto corresponde a 64,94\% da área, e apresenta-se desta forma porque os locais onde foram demarcadas as 60 parcelas se encerraram em três pontos extremos na área total de $1 \mathrm{Km}^{2}$. Assim, o programa $S U R F E R^{\circledR}$ reconheceu que nesta área central não possuía indivíduos.

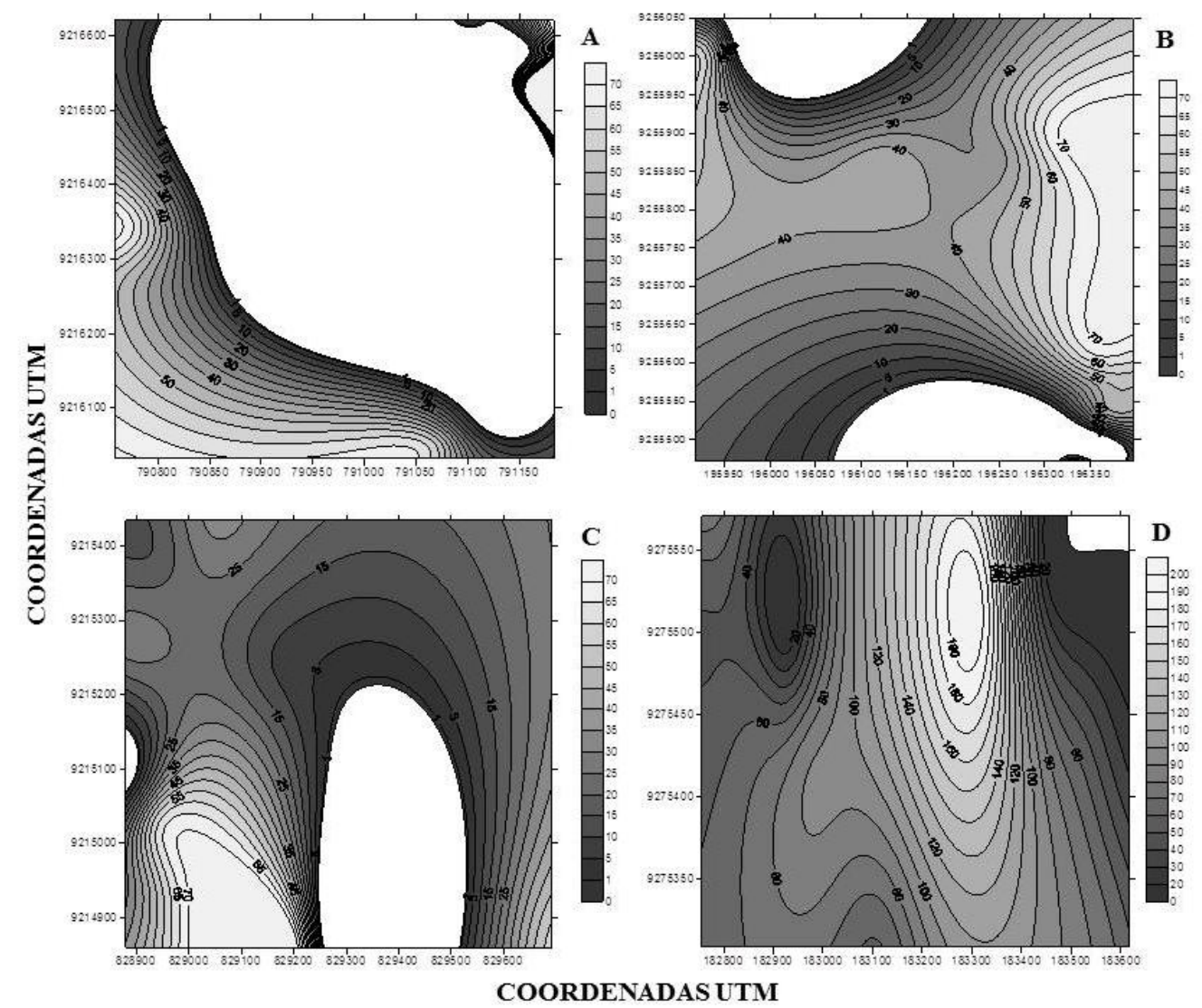

Figura 4. Mapas de isolinhas de distribuição espacial das classes de diâmetro $(\mathrm{em} \mathrm{cm})$ Spondias tuberosa Arruda por parcela em quatro áreas de Caatinga, nos municípios de Soledade (A), Solânea (B), Pocinhos (C) e Cacimba de Dentro (D). Contour maps of spatial distribution of diameter classes (in cm) of Spondias tuberosa Arruda per plot in four areas of Caatinga, in the counties of Soledade (A), Solânea (B), Pocinhos (C) and Cacimba de Dentro (D).

Fonte: Autoria própria. Own authorship.

Em Pocinhos observou-se que 24,12\% da área foi amostrada com plantas de diâmetro variando de 1 a $10 \mathrm{~cm}$, em 36,17\% da área observou-se plantas de diâmetro de 15 a $25 \mathrm{~cm}$, plantas com diâmetros de 30 a $40 \mathrm{~cm}$ somaram-se 8,38\%, nos diâmetros de 45 a $55 \mathrm{~cm}$ foram encontradas $5,20 \%$ de indivíduos e representando os exemplares com diâmetro acima de 60 cm estavam 19,37\% (Figura 4C).

No Curimataú Oriental, Solânea representou os indivíduos com diâmetro de até $10 \mathrm{~cm}$ com 11,55\%; em 17,61\% da área estavam as plantas com 15 a $25 \mathrm{~cm}$ de caule; em 32,01\%, a 
maior porção desta área, foram amostrados os diâmetros de 30 a 40 cm; já os representantes de 45 a $55 \mathrm{~cm}$ compreenderam a 12,05\% e os maiores que $60 \mathrm{~cm}$ somaram-se 12,50\% (Figura 4B).

No município vizinho da mesma microrregião, Cacimba de Dentro, os diâmetros foram em classes maiores devido à amostragem de plantas mais velhas e ausência de indivíduos jovens $(<10 \mathrm{~cm})$, se configurando possivelmente na área em estágio de desenvolvimento ontogenético mais avançado quando comparados com as demais em estudo, visto que não se verificou a presença de indivíduos regenerantes da espécie no local de estudo. Sendo assim, no intervalo entre 20 a $50 \mathrm{~cm}$ de diâmetro foram observadas $20,27 \%$ das plantas; nos diâmetros entre 60 e $90 \mathrm{~cm}$ amostrou-se 38,05\%; plantas com caules de 1 a 1,30 m somaramse $20,03 \%$ e as que possuem de 1,40 a $1,70 \mathrm{~m}$ apresentaram $11,26 \%$; para os diâmetros maiores que $1,80 \mathrm{~m}$ foram 4,27\% (Figura 4D).

Alves Júnior et al. (2013) analisando a estrutura da regeneração natural das espécies lenhosas de área de caatinga no município de Floresta-PE verificaram que foi amostrado um único indivíduo da espécie $S$. tuberosa, cujo padrão do índice de agregação (IGA) foi uniforme e diâmetro na classe II $(51-100 \mathrm{~cm})$. Para os autores esse comportamento demonstra indícios de que algumas espécies da Caatinga não dispõem de recrutamentos contínuos.

A Figura 5 apresenta a estrutura hipsométrica (classes de altura em $\mathrm{m}$ ) dos espécimes de S. tuberosa Arruda nas quatro áreas experimentais de Caatinga dos municípios amostrados. Nas três primeiras áreas foram encontradas seis das nove classes de altura estabelecidas, já em Cacimba de Dentro foram encontradas apenas cinco.

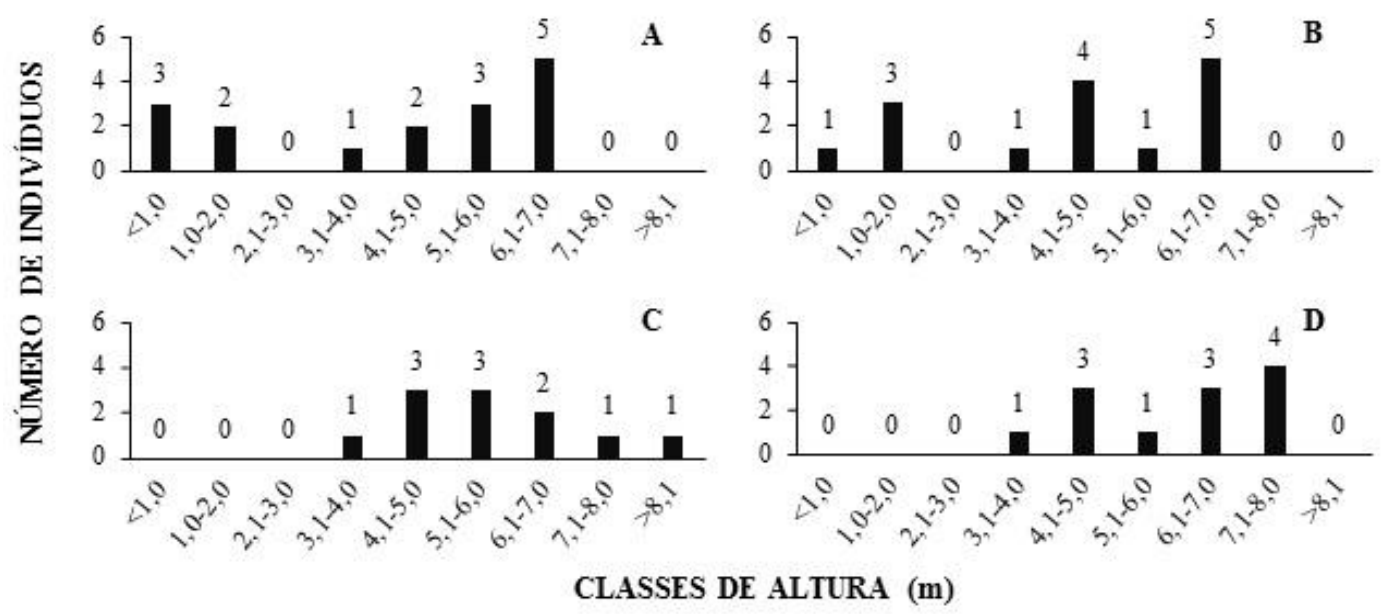

Figura 5. Estrutura hipsométrica de Spondias tuberosa Arruda por parcela em quatro áreas de Caatinga, nos municípios de Soledade (A), Solânea (B), Pocinhos (C) e Cacimba de Dentro (D). Hypsometric structure of Spondias tuberosa Arruda per plot in four areas of Caatinga, in the counties of Soledade (A), Solânea (B), Pocinhos (C) and Cacimba de Dentro (D). Fonte: Autoria própria. Own authorship.

Em Soledade (Figura 5A) este parâmetro apresentou-se bastante semelhante ao histograma de classes de diâmetro. A maior parte dos indivíduos encontrou-se na sétima classe, ou seja, representantes com altura variando entre 6,1-7,0 m (31,25\%), seguida da primeira e sexta classe com indivíduos com porte menor que um metro e entre 5,1-6,0 m respectivamente $(18,75 \%)$ e da segunda $(1,0-2,0 \mathrm{~m})$ e quinta classe $(4,1-5,0 \mathrm{~m}) \mathrm{com} 12,5 \%$ 
dos indivíduos cada. Na caatinga da mesma microrregião, em Pocinhos, a maior parte dos indivíduos permearam as classes hipsométricas de 4,1- 5,0 m e 5,1-6,0 m, ambas com 27,27\% e 6,1-7,0 m (18,18\%), sendo a única área com uma planta amostrada com altura na última classe, medindo 14,30 m (Figura 5C).

Com o estudo da estrutura vertical, é possível analisar o estágio de desenvolvimento da floresta, com base na distribuição dos indivíduos nos diferentes estratos, juntamente com os dados obtidos na distribuição diamétrica. Sendo assim, denota-se que dentre os fragmentos estudados, os localizados nos municípios de Solânea e Pocinhos possuem mais indivíduos em estádio inicial de sucessão (regeneração) com o maior número de espécime situados no primeiro estrato (classes menores), que as demais localidades.

Em Solânea, as classes de altura mais evidentes foram 6,1-7,0 m (33,33\%), 4,1-5,0 m (26,67\%) e 1,0-2,0 m (20\%), na Figura 5B, e em Cacimba de Dentro, como não possui indivíduos regenerantes amostrados, assim como em Pocinhos, só apresentou indivíduos da quarta à oitava classe, sendo mais relevantes as compreendidas entre 7,1-8,0 m (33,33\%), 4,15,0 m e 6,1-7,0 m (25\% cada), na Figura 5D.

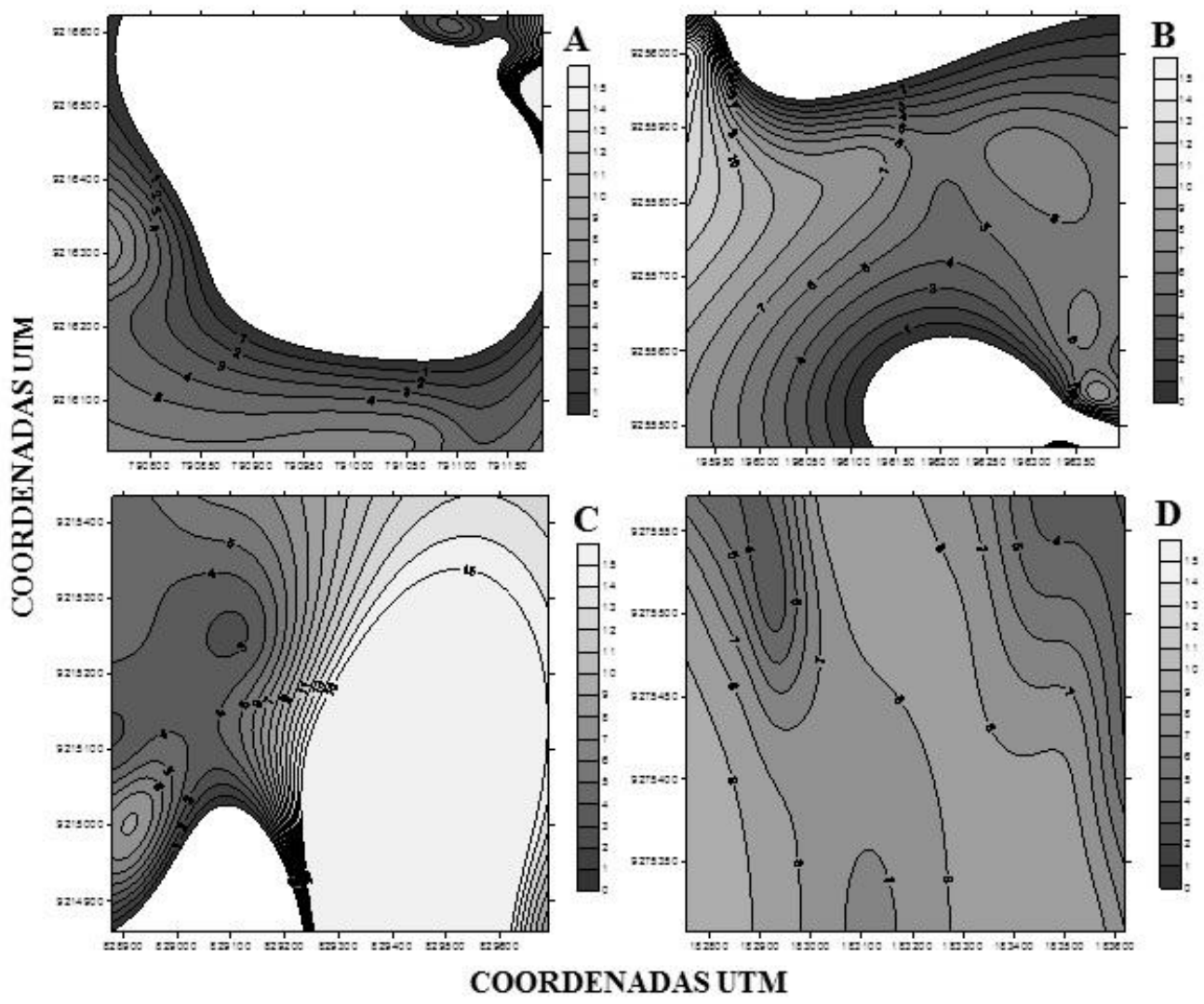

Figura 6. Mapas de isolinhas de distribuição espacial das classes de altura (em metros) de Spondias tuberosa Arruda por parcela em quatro áreas de Caatinga, nos municípios de Soledade (A), Solânea (B), Pocinhos (C) e Cacimba de Dentro (D). Contour maps of spatial distribution of height classes (in meters) of Spondias tuberosa Arruda per plot in four areas of Caatinga, in the counties of Soledade (A), Solânea (B), Pocinhos (C) and Cacimba de Dentro (D).

Fonte: Autoria própria. Own authorship. 
A Figura 6 apresenta os mapas de disposição de isolinhas de distribuição espacial das classes de altura (em metros) da espécie por parcela nas quatro áreas. De acordo com a Figura, no município de Soledade foi mais expressiva a presença de indivíduos entre 1,0-3,0 $\mathrm{m}(16,79 \%)$ e 4,0-6,0 $\mathrm{m}(16,70 \%)$, sendo as alturas superiores a estas, presentes em menos de $1 \%$ cada (Figura 6A). Em Pocinhos, ao contrário, teve uma expressividade em todos os intervalos de alturas, se configurando da seguinte forma 1,0-3,0 m (13,78\%), 4,0-6,0 m (17,21\%), 7,0-9,0 m (6,86\%), 10,0-12,0 m (7,37\%), e 13,0-15,0 m (47,90\%), na Figura 6C. Para o município de Pocinhos, a Figura 5 apresenta no gráfico $\mathrm{C}$ uma árvore com mais de 8,1 $\mathrm{m}$ de altura, mas as isolinhas da Figura 6 apresentam valores até 15,0 $\mathrm{m}$ nos mapas. Isto ocorre devido à predição que o Programa $S U R F E R^{\circledR}$ faz quando da elaboração dos mapas feitos a partir das coordenadas geográficas coletadas.

Para Solânea as alturas mais nítidas foram entre os menores intervalos, contendo poucas plantas acima de $7 \mathrm{~m}$ na área. Sendo assim, o resultado se configurou em: 1,0-3,0 m (18,21\%), 4,0-6,0 m (39,52\%) e 7,0-9,0 m (14,26\%) (Figura 6B). Em Cacimba de Dentro ocorreu o mesmo, mas, neste caso, as árvores acima de $10 \mathrm{~m}$ se mostraram ausentes, estando mais da metade com altura entre 7,0-9,0 m (69,93\%). Outros intervalos com porcentagens maiores que $1 \%$ do local foram os de 1,0-3,0 m (5,73\%), e 4,0-6,0 m (24,58\%), na Figura 6D.

É possível notar que entre os dois tipos de mapas das Figuras 4 e 6 (diâmetro do caule e altura, respectivamente) existe certa semelhança nas disposições das isolinhas. Isso reflete a forma do desenvolvimento da espécie, a qual adota determinadas medidas análogas como padrão.

Tabela 1. Descritores da estrutura horizontal de Spondias tuberosa Arruda em agroecossistemas dos municípios de Soledade, Solânea, Pocinhos e Cacimba de Dentro em ordem decrescente com base no índice de agregação da espécie (IGA). Descriptors of the horizontal structure of Spondias tuberosa Arruda in agroecosystems in the counties of Soledade, Solânea, Pocinhos and Cacimba de Dentro in descending order based on the species aggregation index (IGA).

\begin{tabular}{|c|c|c|c|c|c|c|c|}
\hline Área amostral & $\begin{array}{r}\mathrm{AB} \\
\left(\mathrm{m}^{2}\right) \\
\end{array}$ & $\begin{array}{c}\text { DA } \\
\text { (ind. ha) }\end{array}$ & $\begin{array}{l}\text { FA } \\
(\%) \\
\end{array}$ & $\begin{array}{c}\text { DoA } \\
\text { (ind. ha) }\end{array}$ & $\mathrm{U}$ & IGA & $\begin{array}{c}\text { Classificação } \\
\text { IGA }\end{array}$ \\
\hline Soledade & 2,03 & 0,16 & 16,67 & 0,0203 & 10 & 1,46 & $\begin{array}{c}\text { Tend. ao } \\
\text { Agrupamento }\end{array}$ \\
\hline Solânea & 1,55 & 0,15 & 21,67 & 0,0155 & 13 & 1,02 & $\begin{array}{c}\text { Tend. ao } \\
\text { Agrupamento }\end{array}$ \\
\hline Pocinhos & 0,78 & 0,11 & 18,33 & 0,0078 & 11 & 0,91 & Uniforme \\
\hline $\begin{array}{l}\text { Cacimba de } \\
\text { Dentro }\end{array}$ & 5,48 & 0,12 & 20,00 & 0,0548 & 12 & 0,90 & Uniforme \\
\hline
\end{tabular}

Em que: $\mathrm{AB}=$ Área Basal; DA = Densidade Absoluta; FA = Frequência Absoluta; DoA = Dominância Absoluta; $\mathrm{U}=$ Número de unidades amostrais em que ocorre a espécie; IGA = Índice de Agregação de Espécie. In what: $A B=$ Basal area $; D A=$ Absolute Density; $F A=$ Absolute Frequency; $D o A=$ Absolute Dominance $U=$ Number of sample units in which the species occurs; IGA = Species Aggregation Index.

Fonte: Autoria própria. Own authorship.

A Tabela 1 apresenta os descritores de estrutura horizontal da espécie adotados neste trabalho para as quatro áreas amostradas bem como os valores e classificações dos índices de 
agregação, revelando que Soledade demonstrou maior densidade absoluta (DA = 0,16 ind. ha), porém, frequência absoluta inferior às demais $(\mathrm{FA}=16,67 \%)$ e, por conseguinte uma dominância absoluta de 0,0203 ind. ha; já Solânea teve a segunda maior densidade absoluta (DA $=0,15$ ind. ha) e a maior frequência absoluta de $(\mathrm{FA}=21,67 \%)$, com 0,0155 ind. ha de dominância absoluta.

Em Pocinhos, foi evidenciada a menor densidade absoluta (DA $=0,11$ ind. ha), bem como menor dominância absoluta $(0,0078$ ind. ha), tendo $F A=18,33 \%$. Para Cacimba de Dentro os valores dos parâmetros amostrados foram os seguintes: DA =0,12 ind. ha, FA = $20 \%$, e DoA $=0,0548$ ind. ha. Sendo a área com maior dominância absoluta, é possível afirmar que em Cacimba de Dentro ocorrem indivíduos mais desenvolvidos em relação às outras áreas estudas.

A Tabela 1 ao apresentar os valores e a classificação do índice de agregação da espécie (IGA), revela que as áreas de Soledade e Solânea possuem similaridade, ambas com tendência ao agrupamento (IGA>1,0 e <2,0), embora Solânea esteja no limite entre um padrão de distribuição aleatória $(\mathrm{IGA}=1,0)$. Para as áreas de Pocinhos e Cacimba de Dentro, que não apresentaram nenhum indivíduo regenerante, o padrão de distribuição da espécie se configura como uniforme $(\mathrm{IGA}<1,0)$.

Muitas espécies, como o umbuzeiro, possuem diásporos com características próprias (frutos carnosos, sementes leves, etc.) que ampliam sua capacidade de dispersão por determinados agentes, os quais facilitam a dispersão. Van der Pijl (1982) nomeou este mecanismo de síndrome de dispersão. A tendência ao agrupamento e a agregação são típicos de espécies que possuem síndromes zoocórica e autocórica (JANZEN, 1976). A dispersão do umbuzeiro na natureza é realizada por diversos agentes encontrados na Caatinga, como o veado-catingueiro (Mazama gouazoubira), a cotia (Dasyprocta cf. prymnolopha), o caititu (Tayassu tajacu), a raposa (Dusicyon thous) e o tatu-peba (Euphractus sexcinctus) (CAVALCANTI; RESENDE; BRITO, 2003), como também o caprino (Capra hircus) em áreas de Caatinga não preservada, dentre outros animais, configurando, assim, dispersão zoocórica para esta espécie. Mas apesar das quatro áreas terem predisposição para possuírem padrão com tendência ao agrupamento, existem outros fatores que influenciam na supressão das plantas em seus ambientes naturais, como a predação de indivíduos regenerantes por animais, o desmatamento de áreas de Caatinga para uso da agropecuária, os danos causados por pragas às sementes, dentre outros.

Diante dos parâmetros estruturais analisados, observam-se populações predominantemente estabelecidas. Em alguns locais foram observados elevada densidade relativa de regenerantes, que garantem a perpetuação da espécie, mas a presença de indivíduos adultos foi mais evidente.

A insuficiência de indivíduos jovens em ambientes de Caatinga diminui o recrutamento de novas plantas da espécie, e consequentemente reduz a tendência ao agregamento. Para a espécie S. tuberosa Arruda já foi reportada em diversos trabalhos a falta de indivíduos regenerantes. Andrade et al. (1999) relataram que em estudo realizado em quatro municípios da microrregião do Cariri paraibano para caracterização de populações de umbuzeiro, foi localizada apenas uma planta avaliada como jovem. De acordo com estes autores, a ausência 
de plantas jovens demonstra que esta espécie corre risco de desaparecer em poucas décadas caso não se tomem medidas preservacionistas.

Em trabalho realizado sobre manejo da Caatinga para produção de forragem na região semiárida do estado de Pernambuco, foram identificados três indivíduos jovens por hectare (ALBUQUERQUE; BANDEIRA, 1995). Em outro trabalho realizado nessa mesma área, durante seis anos, visando o levantamento da densidade populacional das espécies da Caatinga submetidas a pastejo contínuo, Albuquerque (1999) não identificou nenhuma planta jovem.

Resultados semelhantes foram encontrados em estudo de Cavalcanti e Resende (2004), os quais selecionaram 17 plantas adultas para colheita de sementes e encontraram apenas duas plantas jovens em fase de crescimento, sendo a primeira com altura de 1,75 m, e diâmetro basal do caule de $3,2 \mathrm{~cm}$, distando $80 \mathrm{~m}$ da planta adulta mais próxima, e a segunda planta com altura de 2,63 m e diâmetro basal do caule de 5,06 cm, se encontrando $163 \mathrm{~m}$ da planta adulta mais próxima e a $356 \mathrm{~m}$ em linha reta da outra planta jovem.

Sabe-se que os organismos atravessam fases sequenciais do nascimento à morte, caracterizando a idade cronológica, e essa série de fases de desenvolvimento de um indivíduo é conhecida por ontogenia. Fabricante e Andrade (2007), em estudo de estrutura de um remanescente de Caatinga de $4.000 \mathrm{~m}^{2}$ no município de Santa Luzia, PB, microrregião do Seridó Ocidental, amostraram 2.368 indivíduos de 22 espécies, dentre os quais apenas um correspondia a um espécime de $S$. tuberosa Arruda enquadrado no estágio ontogenético de adulto, revelando, assim como neste trabalho, além de uma densidade baixa, a insuficiência de indivíduos regenerantes.

\section{CONCLUSÕES}

As áreas de Soledade e Solânea são as que possuem melhor estado de conservação da espécie S. tuberosa Arruda, quando comparadas às áreas de Pocinhos e Cacimba de Dentro, sendo mais abundantes os indivíduos em recrutamento, ocorrendo maior abundância absoluta por área e possuindo padrão de tendência ao agrupamento.

Nas caatingas de Pocinhos e Cacimba de Dentro ocorre ausência de indivíduos regenerantes de $S$. tuberosa Arruda, sendo encontrados somente indivíduos adultos em estádios ontogenéticos avançados e possuindo padrão de distribuição uniforme.

A caatinga de Soledade possui maior densidade absoluta da espécie S. tuberosa Arruda, e a de Pocinhos, a menor, quando comparadas. Já em termos de frequência absoluta, Solânea detém a maior e Soledade a menor.

Como este é um trabalho descritivo, exploratório, em uma área de Caatinga, é interessante que seja feita esta mesma prospecção em outras áreas semelhantes, bem como outros estudos sobre a dinâmica de populações de $S$. tuberosa Arruda devem ser implementados visando obter taxas de mortalidade, recrutamento, crescimento e reprodução, além de estudos de caracterização genética, para um maior entendimento das estratégias de 
crescimento e de desenvolvimento dos espécimes em seus diferentes ecossistemas, servindo para análises sobre a preservação da espécie.

\section{AGRADECIMENTOS}

À Coordenação de Aperfeiçoamento de Pessoal de Nível Superior (CAPES) pela oferta da bolsa de mestrado, e à colaboração voluntária dos agricultores; fatores imprescindíveis que possibilitaram a realização desta pesquisa.

\section{REFERÊNCIAS BIBLIOGRÁFICAS}

AGÊNCIA EXECUTIVA DE GESTÃO DAS ÁGUAS DA PARAÍBA - AESA. Pluviometria média mensal, João Pessoa, 2015. (Documento interno).

ALBUQUERQUE, S. G. Caatinga vegetation dynamics under various grazing intensities by steers in the semi-arid Northeast, Brazil. Journal of Range Management, Tucson, v. 52, n.3, p.241-248, 1999.

ALBUQUERQUE, S. G.; BANDEIRA, G. R. Effect of thinning and slashing on forage phytomass from a caatinga of Petrolina, Pernambuco, Brazil. Pesquisa Agropecuária Brasileira, Brasília, v. 30, n. 6, p.885-891, 1995.

ALVES JÚNIOR, F. T.; FERREIRA, R. L. C.; SILVA, J. A. A.; MARAGON, L. C.; CESPEDES, G. H. G. Regeneração natural de uma área de caatinga no sertão Pernambucano, nordeste do Brasil. Cerne, Lavras, v. 19, n. 2, p.229-235, 2013.

ALVES, J. J. A.; SOUZA, E. N.; NASCIMENTO, S. S. Núcleos de desertificação no Estado da Paraíba. Revista Ra'e Ga, Curitiba, v. 1, n. 17, p.139-152, 2009.

ANDRADE, L. A.; COSTA, N. P.; SILVA, F. S.; PEREIRA, I. M. Caracterização de populações de umbuzeiro (Spondias tuberosa Arr. Cam.) ocorrentes no Cariri Paraibano. In: CONGRESSO NACIONAL DE BOTÂNICA, 50., 1999, Blumenau. Anais [...] Blumenau: UFPR/SBB, 1999. p. 267.

ANJOS, A.; MAZZA, M. C. M.; SANTOS, A. C. M. C.; DELFINI, L. T. Análise do padrão de distribuição espacial da Araucária (Araucaria angustifolia) em algumas áreas do Paraná, utilizando a função K de Ripley. Scientia Forestalis, Piracicaba, v. 66, n. 1, p.36-45, 2004.

ANJOS, A; COUTO, H. T. Z.; BATISTA, J. L. F.; REIS, A. Análise de um efeito de um manejo em regime de rendimento sustentável sobre o padrão de distribuição espacial do palmiteiro (Euterpe edulis Martius), utilizando a função $\mathrm{K}$ de Ripley. Revista Árvore, Viçosa, v. 22, n. 2, p.215-225, 1998.

ARAÚJO, F. S.; RODAL, M. J. N.; BARBOSA, M. R. V. (Orgs.) Análise das variações da biodiversidade do bioma caatinga. Brasília, DF: Ministério do Meio Ambiente, 2005. 446 p.

ARAUJO, K. D.; PARENTE, H. N.; SILVA, E. E.; RAMALHO, C. I.; DANTAS, R. T.; ANDRADE, A. P.; SILVA, D. S. Estrutura fitossociológica do estrato arbustivo-arbóreo em 
áreas contíguas de Caatinga no Cariri Paraibano. Brazilian Geographical Journal, Uberlândia, v. 3, n. 1, p.155-169, 2012.

ARAÚJO, L. V. C. Composição florística, fitossociologia e influência dos solos na estrutura da vegetação em uma área de caatinga no semiárido paraibano. $2007.121 \mathrm{f}$. Tese (Doutorado em Agronomia) - Centro de Ciências Agrárias, Universidade Federal da Paraíba, João Pessoa, 2007.

BRASIL. Ministério de Minas e Energia. Secretaria de Planejamento e Desenvolvimento Energético Secretaria de Geologia, Mineração e Transformação Mineral. Companhia de Pesquisa de Recursos Minerais CPRM. Programa de Desenvolvimento Energético dos Estados e Municípios - PRODEEM. Projeto cadastro de fontes de abastecimento por água subterrânea. Diagnóstico do município de Cacimba de Dentro, estado da Paraíba. João de Castro Mascarenhas, Breno Augusto Beltrão, Luiz Carlos de Souza Junior, Franklin de Morais, Vanildo Almeida Mendes, Jorge Luiz Fortunato de Miranda (org.). Recife: CPRM/PRODEEM, 2005a. 19 p. Disponível em: http://rigeo.cprm.gov.br/jspui/bitstream/doc/15887/1/Rel_Cacimba_Dentro.pdf/. Acesso em: 19 nov. 2019.

BRASIL. Ministério de Minas e Energia. Secretaria de Planejamento e Desenvolvimento Energético Secretaria de Geologia, Mineração e Transformação Mineral. Companhia de Pesquisa de Recursos Minerais CPRM. Programa de Desenvolvimento Energético dos Estados e Municípios - PRODEEM. Projeto cadastro de fontes de abastecimento por água subterrânea. Diagnóstico do município de Pocinhos, estado da Paraíba. João de Castro Mascarenhas, Breno Augusto Beltrão, Luiz Carlos de Souza Junior, Franklin de Morais, Vanildo Almeida Mendes, Jorge Luiz Fortunato de Miranda (org.). Recife: CPRM/PRODEEM, 2005b. 19 p. Disponível em: http://rigeo.cprm.gov.br/xmlui/bitstream/handle/doc/16273/Rel_Pocinhos.pdf?sequence=1/. Acesso em: 19 nov. 2019.

BRASIL. Ministério de Minas e Energia. Secretaria de Planejamento e Desenvolvimento Energético Secretaria de Geologia, Mineração e Transformação Mineral. Companhia de Pesquisa de Recursos Minerais CPRM. Programa de Desenvolvimento Energético dos Estados e Municípios - PRODEEM. Projeto cadastro de fontes de abastecimento por água subterrânea. Diagnóstico do município de Solânea, estado da Paraíba. João de Castro Mascarenhas, Breno Augusto Beltrão, Luiz Carlos de Souza Junior, Franklin de Morais, Vanildo Almeida Mendes, Jorge Luiz Fortunato de Miranda (org.). Recife: CPRM/PRODEEM, 2005c. 20 p. Disponível em: http://rigeo.cprm.gov.br/xmlui/bitstream/handle/doc/16402/Rel_Solânea.pdf?sequence=1/. Acesso em: 19 nov. 2019.

BRASIL. Ministério de Minas e Energia. Secretaria de Planejamento e Desenvolvimento Energético Secretaria de Geologia, Mineração e Transformação Mineral. Companhia de Pesquisa de Recursos Minerais CPRM. Programa de Desenvolvimento Energético dos Estados e Municípios - PRODEEM. Projeto cadastro de fontes de abastecimento por água subterrânea. Diagnóstico do município de Soledade, estado da Paraíba. João de Castro Mascarenhas, Breno Augusto Beltrão, Luiz Carlos de Souza Junior, Franklin de Morais, 
Vanildo Almeida Mendes, Jorge Luiz Fortunato de Miranda (org.). Recife: CPRM/PRODEEM, 2005d. 19 p. Disponível em: http://rigeo.cprm.gov.br/xmlui/bitstream/handle/doc/16425/Rel_Soledade.pdf?sequence=1/. Acesso em: 19 nov. 2019.

CARLSON, R. E.; FOLEY, T. A. The parameter R2 in multiquadric interpolation. Computers \& Mathematics with Applications, New York, v. 21, n. 9, p.29-42, 1991.

CAVAlCANTI, N. B.; RESENDE, G. M. Danos Provocados por Insetos a Sementes do Imbuzeiro no Semi-Árido do Nordeste Brasileiro. Caatinga, Mossoró, v.17, n. 2, p.93-97, 2004.

CAVALCANTI, N. B.; RESENDE, G. M.; BRITO, L. T. L. Regeneração natural e dispersão de sementes do imbuzeiro (Spondias tuberosa Arruda) no sertão de Pernambuco. Engenharia Ambiental, Espírito Santo do Pinhal, v. 6, n. 2, p.342-357, 2009.

EMPRESA BRASILEIRA DE PESQUISA AGROPECUÁRIA - EMBRAPA. Solos do Nordeste. Recife: EMBRAPA Solos, 2006. Disponível em: http://www.uep.cnps.embrapa.br/solos/. Acesso em: 04 fev. 2015.

FABRICANTE, J. R.; ANDRADE, L. A. Análise estrutural de um remanescente de caatinga do seridó paraibano. Oecologia Brasiliensis, Rio de Janeiro, v. 11, n. 3, p.341-349, 2007.

FRANCISCO, P. R. M. Classificação e mapeamento das terras para mecanização agrícola do estado da Paraíba utilizando sistema de informações geográficas. 2010. $122 \mathrm{f}$. Dissertação (Mestrado em Manejo de Solo e Água) - Universidade Federal da Paraíba, Areia, 2010.

GOMES, L. M.; AZEVEDO, P. V.; SILVA, V. P. R. Áreas do estado da Paraíba com predisposição ambiental ao processo de desertificação. In: CONGRESSO BRASILEIRO DE AGROMETEOROLOGIA, 16., 2009, Belo Horizonte. Anais [...] Belo Horizonte: UFV/SBA, 2009, v. 1, p.1-5.

JACOMINE, P. K. T. A nova classificação brasileira de solos. Anais da Academia Pernambucana de Ciência Agronômica, Recife, v. 5-6, n. 1, p.161-179, 2009.

JAKOB, A. A. E. A Krigagem como método de análise de dados demográficos. In: ENCONTRO DA ASSOCIAÇÃO BRASILEIRA DE ESTUDOS POPULACIONAIS, 13., 2002, Ouro Preto. Anais [...] Ouro Preto: UFMG/ABEP, 2002, v. 1, p.1-21.

JANZEN, D. H. Why bamboos take so long to flower. Annual Review of Ecology and Systematics, Palo Alto, v. 7, n. 1, p.347-391, 1976.

LAMPRECHT, H. Ensayo sobre unos métodos para el análisis estructural de los bosques tropicales. Acta Cientifica Venezoelana, Caracas, v. 13, n. 2, p.57-65, 1962.

LOPES, P. S. N.; MAGALHÃES, H. M.; GOMES, J. G.; BRANDÃO JÚNIOR, D. S.; ARAÚJO, V. D. Superação da dormência de sementes de umbuzeiro (Spondias tuberosa, Arr. Cam.) utilizando diferentes métodos. Revista Brasileira de Fruticultura, Jaboticabal, v. 31, n. 3, p.872-880, 2009. 
MCGINNIES, W. G. The relationship between frequency index and abundance as applied to plant populations in a semi-arid region. Ecology, Hoboken, v. 15, n. 3, p.263-282, 1934.

NEVES, O. S. C.; CARVAlHO, J. G. Tecnologia da Produção do Umbuzeiro (Spondias tuberosa Arr. Cam.). Lavras: UFLA, 2005. 101 p.

PADILLA, F. M.; PUGNAIRE, F. I. Sucesión y restauración em ambientes semiáridos. Ecosistemas, Madrid, v. 13, n. 1, p.55-58, 2004.

PEREIRA FILHO, J. M.; SILVA, A. M. A.; CÉZAR, M. F. Manejo da Caatinga para produção de caprinos e ovinos. Revista Brasileira de Saúde e Produção Animal, Salvador, v. 14, n. 1, p.77-90, 2013.

RAMALHO, C. I. Estrutura da vegetação e distribuição espacial do licuri (Syagrus coronata (Mart) Becc.) em dois municípios do centro norte da Bahia, Brasil. 2008. $131 \mathrm{f}$. Tese (Doutorado em Agronomia) - Universidade Federal da Paraíba, Areia, 2008.

SÁ SOBRINHO, R. G. Agricultura camponesa no Curimataú Paraibano: entre a subsistência e a sustentabilidade sócio-ambiental. 2010. 203 f. Tese (Doutorado em Sociologia) - Universidade Federal de Campina Grande, Campina Grande, 2010.

SANTANA, J. A. S.; SOUTO, J. S. Diversidade e estrutura fitossociológica da caatinga na estação ecológica do Seridó-RN. Revista de Biologia e Ciências da Terra, São Cristóvão, v. 6, n. 2, p.232-242, 2006.

VAN DER PIJL, L. Principles of dispersal in higher plants. 3. ed. Berlin: Springer-Verlag, 1982, $218 \mathrm{p}$.

YADAV, A. S.; GUPTA, S. K. Natural regeneration of tree species in a tropical dry deciduous thorn forest in Rajasthan, India. National Institute of Ecology, New Delhi, v. 20, n. 1, p.5-14, 2009. 